\title{
Synergistic Antibacterial Activity of Cassia auriculata L. Flowers and Ofloxacin
}

\author{
Varadharajan Subhadra Devi*, Ushanandhini, Kuppusamy AsokKumar, Muthuswamy UmaMaheswari, \\ AndichettiarThirumalaisamy Sivashanmugham, Puliyath Jagannath
}

Department of Pharmacology, College of Pharmacy, Sri Ramakrishna Institute of Paramedical Sciences, Coimbatore -641044, India.

\author{
(Received 20 August 2011; Accepted 22 October 2011)
}

\begin{abstract}
A cost effective antimicrobial agent for multi drug resistant organisms, based on the synergistic activity of ofloxacin with ethanolic extract of flowers of Cassia auriculata was determined. The Minimum Inhibition Concentration (MIC) of ethanolic extract using 3 different Gram-positive bacteria, such as Staphylococcus aureus NCIM 2127 and Bacillus subtilis NCIM 2010, and Gram-negative bacteria Escherichia coli NCIM 2118 was found to be around 1024 to $2048 \mathrm{mg} / \mathrm{ml}$. The synergistic activity varied using checkerboard synergy technique. The results of the conducted experiments showed in vitro interactions between antimicrobial agents and plant extract were additive against the strains tested, it also showed synergistic effects between combination of antibiotics and plant extracts with significant reduction in the MICs of the test antibiotics against these strains. It showed maximum synergistic activity against Gram-negative species. The higher synergistic rate was attained against $E$. coli NCIM 2118, and lowest synergistic shows against S. aureus NCIM 2127.
\end{abstract}

Key words: Antibmicrobial activity, Minimum Inhibition Concentration (MIC), Cassia auriculata, Ofloxacin.

The wide use of antibiotics in the treatment of bacterial infections has led to the emergence and spread of resistant strains. Emergence of multiple drug resistance to human pathogenic organisms has necessitated a search for new antimicrobial substance from other sources including plants ${ }^{1}$.

Natural products are a source of traditional herbal medicine and are still use in the primary health care system ${ }^{2}$. Antimicrobials of plant origin have enormous therapeutic potential ${ }^{3}$. Extracts from medicinal plants have showed the effectiveness of traditional herbs against microorganisms; as a result, plants are one of the bedrocks for modern medicine to attain new principles ${ }^{4}$. The synergistic effect enables the use of the respective antibiotic when it is no longer effective by itself during therapeutic treatment ${ }^{5}$. Therefore, the present study was undertaken to investigate synergistic activity of ethanol extract of Cassia auriculata with Tetracycline.

The flowers of $C$. auriculata were collected, thoroughly dried under shade, powdered mechanically and sieved through No.20 mesh sieve. The finely powdered flowers were kept in an airtight container until the time of use. The extraction of flower was carried out by continuous hot percolation method using $95 \%$ ethanol. The extract was concentrated under controlled temperature between $40-50^{\circ} \mathrm{C}$. The percentage yield of the C. auriculata flower extract was $18.2 \%$.
The bacterial strains used were Escherichia coli NCIM 2118, Bacillus subtilis NCIM 2010, and Staphylococcus aureus NCIM 2127. All the organisms were grown over night $(24 \mathrm{hr})$ at $37^{\circ} \mathrm{C}$ on Nutrient Agar (NA) and transferred a loop full to $10 \mathrm{ml}$ of MuellerHinton (MH) broth and incubated without agitation for $24 \mathrm{hrs}$ at $37^{\circ} \mathrm{C}$. Bacterial inoculum was standardized by matching the turbidity of the culture to $0.5 \mathrm{McF}$ arland standards by diluting with fresh MH broth ${ }^{6}$.

The MICs of various drugs were determined in Muller-Hinton broth (Difco, USA) containing the same volume of medium having different concentration of plant extract. Cells in the test medium were incubated at $37^{\circ} \mathrm{C}$ for $24 \mathrm{~h}$. The MICs were determined as the lowest concentration of antimicrobial agents or the flower extract at which bacterial cells unable to grow.

Synergy testing was performed for 3 strains ( $S$. aureus, $B$. substilis, E. coli) by the checkerboard synergy method in $5 \mathrm{ml}$ test tubes with $\mathrm{MH}$ broth. The concentrations tested for each antimicrobial typically ranged from four concentrations below the MIC to three concentrations above MIC, using 2-fold dilutions of each antimicrobial. The flower extract of $C$. auriculata was tested at concentrations of $128-8192 \mu \mathrm{g} / \mathrm{ml}$ (Drug A). Ofloxacin (Drug B) was tested at concentrations of $0.25-16 \mathrm{mg} / \mathrm{ml}$. The procedure followed by the method described by Ghaly et al. $(2009)^{7}$. 
The results of checkerboard testing were interpreted by the pattern they form on the isobologram. Synergy was determined by calculating the fractional inhibitory concentration (FIC) index as follows: $\mathrm{FIC}$ index: $\mathrm{FIC}_{\mathrm{A}}+\mathrm{FIC}_{\mathrm{B}}=[\mathrm{A}] / \mathrm{MIC}_{\mathrm{A}}+[\mathrm{B}] / \mathrm{MIC}_{\mathrm{B}}$, where [A] is the concentration of drug $\mathrm{A}$ in that is the lowest inhibitory concentration in its row, $\mathrm{MIC}_{\mathrm{A}}$ is the MIC of the organism to Drug A alone. $\mathrm{FIC}_{\mathrm{A}}$ is the $\mathrm{FIC}$ of Drug $\mathrm{A}$ and $[\mathrm{B}], \mathrm{MIC}_{\mathrm{B}}$ and $\mathrm{FIC}_{\mathrm{B}}$ are defined in the same fashion for Drug $B$. Results of synergy testing were defined as follows: $£ 0.5$, synergy; $>0.5$ but $<1$, partial synergy; 1 , additive effect, $>1$ but $<4$, indifference; ${ }^{3} 4$ antagonism ${ }^{8}$.

Results of minimum inhibitory concentration are shown in Table 1. The MIC of $C$. auriculata flower extract ranged between 1024 to $2048 \mathrm{mg} / \mathrm{ml}$, with respect to all the test bacteria. The checkerboard technique was performed to evaluate the interaction of the floral extract in combination with ofloxacin. The FIC indices of the combination for the three bacterial strains are presented in Table 2 .

The MIC of ofloxacin alone to $S$. aureus NCIM 2127 was $2 \mathrm{mg} / \mathrm{ml}$, while in combination with the flower extract, the MIC of ofloxacin to $S$. aureus NCIM 2127 became $1 \mathrm{mg} / \mathrm{ml}$, indicating a twofold decrease in MIC. With flower extract, a six fold decrease in MIC observed from $2048 \mathrm{mg} / \mathrm{ml}$ to $256 \mathrm{mg} / \mathrm{ml}$. the FIC index of the combination was 0.625 . Thus the FIC index of floral extract in combination with ofloxacin showed a partial synergistic effect against $S$. aureus. The MIC of ofloxacin alone to B. subtilis NCIM 2010 was $4 \mathrm{mg} / \mathrm{ml}$, while in combination with floral extract, the MIC of ofloxacin to B. subtilis NCIM 2010 became $1 \mathrm{mg} / \mathrm{ml}$, indicating a fourfold decrease in MIC. With floral extraxt, a fourfold decrease in MIC observed from $1024 \mathrm{mg} / \mathrm{ml}$ to $256 \mathrm{mg} / \mathrm{ml}$. the FIC index of the combination was 0.5 . Therefore, the FIC index of the flower extract in combination with ofloxacin showed a synergistic effect against $B$. subtilis.

For E. coli, similar result was found where a fourfold decrease in MIC was observed when combined with the flower extract. With floral extract, a six fold decrease in MIC observed from $1024 \mathrm{mg} /$ $\mathrm{ml}$ to $128 \mathrm{mg} / \mathrm{ml}$. The FIC index of the combination was 0.375 . The FIC index of floral extract in combination with ofloxacin showed a remarkable synergistic effect against $E$. coli.

With an observation of a FIC index of flower extract-ofloxacin combination against $E$. coli NCIM 2118 exhibited better synergy when compared to other two strains. The calculated FIC indices for $C$. auriculata flower extract-ofloxacin combination against $S$. aureus NCIM 2127, B. subtilis NCIM 2010 and E. coli NCIM 2118 , were depicted on isobologram, where the synergistic antibacterial effect of the flower extract was shown by a concave curve. The FIC index therefore proved significant synergism of C. auriculata flower extract-ofloxacin.
Table 1. Minimum inhibitory concentration (MIC) values of $C$. auriculata flower extract

\begin{tabular}{lc}
\hline Bacterial strains & $\begin{array}{c}\text { MIC }(\mathrm{s})(\mu \mathrm{g} / \mathrm{ml}) \\
\text { C. auriculata flower extract }\end{array}$ \\
\hline Staphylococcus aureus NCIM 2127 & 2048 \\
Bacillus subtilis NCIM 2010 & 1024 \\
Escherichia coli NCIM 2118 & 1024 \\
\hline
\end{tabular}

Table 2. FIC index of CAFE with ofloxacin against bacterial strains

\begin{tabular}{lc}
\hline Name of the organism & FIC index of flower extract-ofloxacin \\
\hline S. aureus NCIM 2127 & 0.625 \\
B. subtilis NCIM 2010 & 0.5 \\
E. coli NCIM 2118 & 0.375 \\
\hline
\end{tabular}

In an attempt to formulate a new synergistic antimicrobial for bacterial strains we combined $C$. auriculata flower extract with ofloxacin. By checherboard synergy technique, C. auriculata flowerl extract and ofloxacin exhibited synergy at sub inhibitory concentration. The exact mechanism of synergy is currently unknown but several hypotheses can be put forward to explain its mechanism of action. Firstly, if the floral extract disrupts lipopolysaccharide of bacterial strain, it may help restoring a porins channel thus facilitating the flow of ofloxacin to target sites. Secondly, it may cause negative effects on the efflux mechanism and let the sufficient concentration of ofloxacin to remain in bacterium thus helping in its increased antimicrobial activity $^{9-11}$. Thirdly, C. auriculata flower extract may be inhibiting protein synthesis as while acting alone it inhibits the growth of bacterial strains tested ${ }^{12}$. Table 1 shows the effect of combination of extracts and antimicrobial agents on the test organisms. Results revealed an increased activity of ofloxacin in the presence of the extracts.

Our results were consistent with previous in vitro studies which reported synergistic effects with significant reduction in the MICs of the antibiotics due to combination of antibiotics with crude plant extracts against bacterial strains. In these experiments, the change in MIC was noticed in plant extracts against ofloxacin including these plant extracts showed weak antibacterial activity. C. auriculata floral extract showed a decrease in MIC to ofloxacin and this could be referred to that these crude extracts have many different phytochemical constituents, which might inhibit bacteria by different mechanisms. This double attack of both agents on different target sites of the bacteria could theoretically lead to either an additive or synergistic effect.

\section{References}

1. Ahmed I, ZBeg A. 2001. Antimicrobial and phytochemical studies on 45 indian medicinal plants against multi-drug resistant human pathogens. $J$ Ethnopharmacol. 74:113-123. 
2. Blanks TS, Brown B, Cosgrave J, Woody V, Bentley, Sullivan N. 1988. "The Body Shop Book of wellbeing Mind, Body and Soul", Ebury Press London. pp 173-192.

3. Salau AO, and Odeleye OM. 2007. Antimicrobial activity of Mucuna pruriens on selected bacteria. African J Biotechnol. 6(18): 20912092.

4. Evans CE, Banso A, Samuel OA. 2002. Efficacy of some nupe medicinal plants against Salmonella typhi: an in vitro study. J.Ethanopharmacol. 80:21-24.

5. Purushotham KG, Arun P, Johnsy jayarani J, Vasnthakumari R, Sankar L, and Bijjam R R. 2010. Synergistic in vitro antibacterial activityof tectona grandis leaves with tetracycline. Int $J$ Pharma Res. 2(1): 519-523.

6. Doughari JH. 2006. Antimicrobial Activity of Tamarindus indica Linn. Trop J Pharmaceut Res. 5(2): 597-603.

7. Ghaly MF, Shalaby MA, Shash SMS, Shehata MN, Ayad AA. 2009. Synergistic Effect of Antibiotics and Plant Extract to Control Clinical
Bacterial Isolates Implicated in Urinary Tract Infections. $J$ App Sci Res. 5(10): 1298-1306.

8. Eliopoulos GM, Moellering RC. Antimicrobial combinations. In: Lorian V, editor. Antibiotics in laboratory medicine, $3^{\text {rd }}$ ed. 1991. Baltimore: the Willimans and Wilkins co. pp. 432-92.

9. Stermitz FR, Lorenz P, Tawara JNL, Zenewicks LA, and Lewis K. 2000. Synergy in a medicinal plant: Antimicrobial action of berberine potentiated by 5 methoxyhydnocarpin, a mult-idrug pump inhibitor. Proc Natl Acad Sci.USA. 97: 1433-1437.

10. Gibbon S, and Udo EE. 2000. The effect of reserpine, a modulator of multi-drug efflux pump, on the in vitro activity of tetracycline against clinical isolates of methicillin resistant Staphylococus aureus (MRSA) possessing the tet $(\mathrm{K})$ determinant. Phytother Res. 14: 139-40.

11. Van BF, Batzi E, and Tulkens PM. 2000. Antibiotic efflux pumps. Biochem Pharmacol. 60: 457-70.

12. Koneman EW, Allen SD, Janda WM, Schreckenberger PC, and Winn WC. 1997. Antimicrobial susceptibility testing, Fifth ed. Colour Atlas and text book of Diagnostic Microbiology. pp.785-798. 